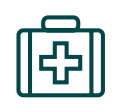

Emergency

Medicine

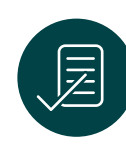

Acceptance rate $40 \%$

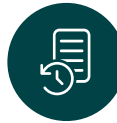

Time to first decision 16 days

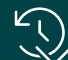

Time to final decision 5 weeks

\title{
Case Reports in Acute Medicine
}

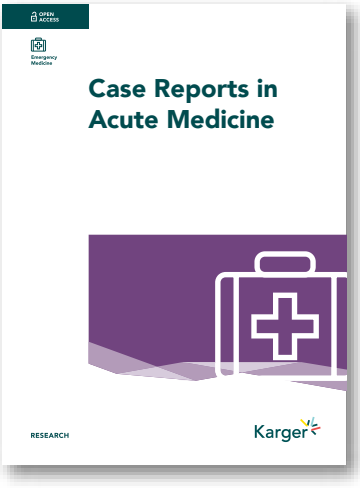

Editors-in-Chief

Naoto Morimura (Tokyo)

Kent Doi (Tokyo)

The first journal on acute medicine dedicated exclusively to case reports

Case Reports in Acute Medicine is a peer-reviewed, Open Access journal that publishes original case studies covering the entire spectrum of acute medicine, including emergency medicine, intensive care, and disaster medicine. The journal will also accept case reports related to the use of novel technologies, both in the area of diagnosis and treatment. Supplementary material is welcomed and free of charge. In this forum, clinicians and researchers communicate their observations to the broadest possible audience in the community.

editorialoffice_cra@ karger.com karger.com/cra 